\title{
Shear Bond Strength Evaluation of Two Adhesive Systems Applied to Etched and Deproteinized Dentin: A Longitudinal Study
}

\author{
${ }^{1}$ Abhinav Sharma, ${ }^{2}$ Shashit Shetty, ${ }^{3}$ Manoj Hans
}

\begin{abstract}
Background: The purpose of this study was to evaluate the shear bond strength (SBS) of two different adhesives to normal and deproteinized dentin at an interval of 24 hours and 6 months.

Materials and methods: Sixty human molars were sectioned and embedded in acrylic resin. Enamel was worn out and dentin was exposed over which acid etching was performed and the specimens were divided into 12 groups $(n=10)$ depending on the adhesive system used, the dentin treatment performed and the length of evaluation. A resin composite was inserted over the prepared area followed by assessment for shear bond strength evaluation.
\end{abstract}

Results: The application of Sodium hypochlorite $(\mathrm{NaOCl})$ significantly increased the SBS values of prime and bond NT but for adper single bond it was decreased. The means values of SBS standard deviation (SD) in MPa for adhesive systems with $5 \%$ $\mathrm{NaOCl}$ for 60 seconds, 120 seconds and without $\mathrm{NaOCl}$ treatment were: prime and bond NT = 12.48 (1.25), 13.01 (1.00) and 17.74 (4.26) and for adper single bond = 10.92 (1.65), 10.96 (2.45) and 7.57 (1.45). Shear bond strength after storage time of 6 months was decreased significantly.

Conclusion: According to the statistical analysis, the results only partly supported the hypotheses and greatly depend on the composition of adhesive system.

Keywords: Dentin, Deproteinization, Resin-infiltrated dentinlayers, Sodium hypochlorite.

How to cite this article: Sharma A, Shetty S, Hans M. Shear Bond Strength Evaluation of Two Adhesive Systems Applied to Etched and Deproteinized Dentin: A Longitudinal Study. J Contemp Dent 2015;5(3):153-157.

Source of support: Nil

Conflict of interest: None

\section{INTRODUCTION}

The foundation for modern adhesive dentistry was laid in 1955, when Buonocore reported that acrylic resin could

${ }^{1}$ Dental Officer (Undergoing Grading), AFMC, Army Dental Corps, ${ }^{2,3}$ Professor

${ }^{1}$ Department of Dental Surgery, AFMC, Nainital, Uttarakhand, India

${ }^{2,3}$ Department of Conservative Dentistry and Endodontics, Kanti Devi Dental College, Mathura, Uttar Pradesh, India

Corresponding Author: Abhinav Sharma, K-6-C Sheikh Sarai 2, New Delhi-110017, India, Phone: 7535053674, e-mail: drabhinavendo@gmail.com be bonded to human enamel that was conditioned with $85 \%$ phosphoric acid for 30 seconds. ${ }^{1}$ Since that time, the dental adhesive systems have evolved from several 'generations' with changes in chemistries, mechanisms, number of bottles, application techniques and clinical effectiveness.

An improvement in dentinal bond strengths by etching was first demonstrated by Fusayama et al in 1979, and dentinal etching has become a fairly common practice since then. $^{2}$

The capability of a strong and durable bond to dentin is an important property of a restorative resin. In conjunction with the bond to enamel, an effective bond to dentin will eliminate the need for retentive undercuts and prevent the formation of marginal gaps.

Enamel is the reliable substrate for bonding, but bonding to dentin remains less reliable and less predictable. Dentin, a substrate rich in collagen fibers, the accession is made with the complete elimination of smear layer and smear plugs by etching. ${ }^{2}$ Great attention has been given about the defective or incomplete penetration of adhesive to the collagen network in dentin. ${ }^{3}$ Researchers found that when a perfect seal of the demineralized surface is not attained, marginal leakage occurs. Thus, a weak zone of demineralized dentin susceptible to failure is created. ${ }^{4}$

Sodium hypochlorite $(\mathrm{NaOCl})$ has been used as dentin deproteinizing agent and investigations have been done on the role of $\mathrm{NaOCl}$ on dentin permeability and adhesion. ${ }^{5-7}$

A combination of substances capable of decalcifying the dentin structure, followed by the application of $\mathrm{NaOCl}$ after complete phosphoric acid etching promotes the appearance of a more porous dentin, with characteristics similar to those of enamel. It also results in widened dentinal tubules without the presence of collagen, which could inhibit adhesive diffusion into the dentin substrate due to drying or excessive humidity, and thus compromising bonding effectiveness. The use of these substances for the purpose of removing the organic dentin material was conceived as a different technique in dental substrate treatment. This technique does not require hybridization with micromechanical infiltration of the resin monomer among the collagen fibers to obtain effective bonding ${ }^{6,7}$ 
The purpose of this study was to evaluate the shear bond strength (SBS) of two different adhesives to normal and deproteinized dentin at an interval of one day (24 hours) and 6 months and to verify whether using $5 \% \mathrm{NaOCl}$ for 60 and 120 seconds for deproteinization produced a similar bond to samples that were not treated with $\mathrm{NaOCl}$.

\section{MATERIALS AND METHODS}

Sixty freshly extracted human molars were collected, cleaned, stored and handled as per the recommendation and the guidelines laid down by ISO TR 11405 (International Organization for Standardization). All the collected teeth were cleared of blood and saliva and stored in distilled water and kept in a freezer until their use.

Using a diamond coated cutting disks, the roots of the specimens were cut off at the cement-enamel junction and the teeth were sectioned along a mesiodistal axial plane, separating them into two equal halves (buccal and lingual). The sectioned teeth were then embedded in acrylic resin; each section measured approximately $40 \times 20 \times 10 \mathrm{~mm}$ (Fig. 1). The vestibular and lingual faces were kept facing outward, maintaining the tooth surface parallel to the horizontal plane.

The remaining dentin thickness was standardized to $2 \mathrm{~mm}( \pm 0.1 \mathrm{~mm})$ with the use of a thickness gauge (API). The vestibular or lingual enamel was worn down using 80 grit silicon carbide abrasive paper (3M), under water cooling (to avoid over warming), until the predetermined thickness was approximated. The smear layer of the dentinal surfaces was standardized using 320, 400, and 600 grit abrasive disks (3M) sequentially for 30 seconds under water cooling at all times.

At this stage, the dentin surface was cleaned with pumice, brush and water till the exposed area was even and smooth. The bond area was delimited with teflon

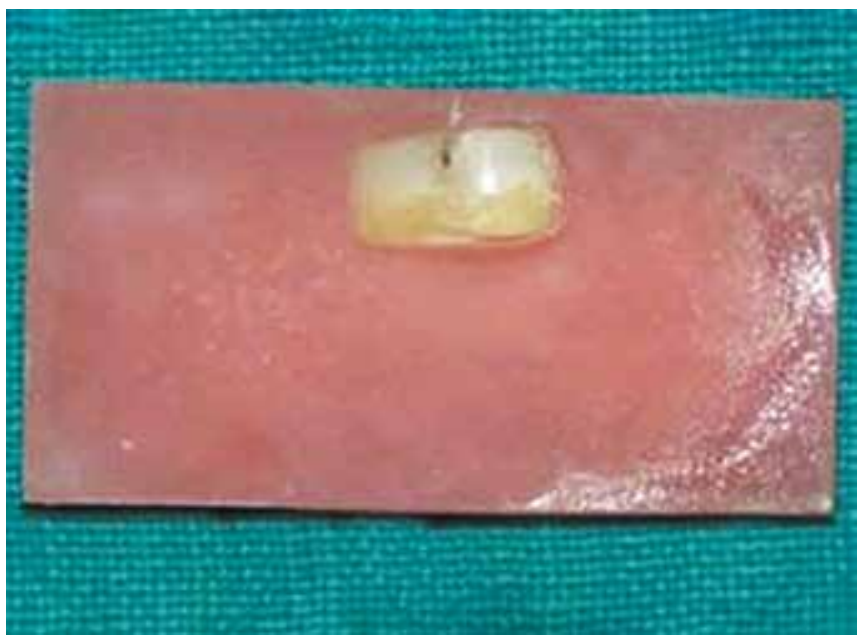

Fig. 1: Tooth embedded in acrylic resin with buccal/lingual face outwards
Table 1: Composition of materials used in the study

\begin{tabular}{ll}
\hline Material & Composition \\
\hline $\begin{array}{l}\text { Prime and Bond } \\
\text { NT (Dentsply/ } \\
\text { Caulk) }\end{array}$ & $\begin{array}{l}\text { Acetone, dimethylacrylate, trimethacrylate, } \\
\text { dipentacriterol pentacrylate phosphate }\end{array}$ \\
$\begin{array}{l}\text { Adper single } \\
\text { bond (3M ESPE) }\end{array}$ & $\begin{array}{l}\text { HEMA, Bis-GMA, dimethylacrylate, } \\
\text { copolymers of polyacrylic and poly-itanconic } \\
\text { acids, water, ethanol, photoinitiators }\end{array}$ \\
$\begin{array}{l}\text { 5\% Sodium } \\
\text { hypochlorite } \\
\text { (Pyrex) }\end{array}$ & $5 \% \mathrm{NaOCl}$ \\
$\begin{array}{l}\text { Z-100 (3M, ESPE) } \\
\text { 35\% Phosphoric } \\
\text { acid gel } \\
\text { (Dentsply) }\end{array}$ & $\begin{array}{l}\text { TEGDMA, Bis-GMA, silica, zirconia } \\
\text { 3esphoric acid gel }\end{array}$ \\
\hline
\end{tabular}

HEMA: Hydroxyethylmethacrylate; BIS-GMA: Bisphenol A glycidyl

dimethacrylate; TEGDMA: Triethylene Glycidyl dimethacrylate

adhesive tape and hollowed in a circular shape, with a standardized diameter of $3 \mathrm{~mm}$.

The specimens were divided into 12 groups, each consisting of 10 specimens (five vestibular and five lingual surfaces, selected at random), according to the adhesive system, dentin treatment, and evaluation time. Evaluations of groups from 1 to 6 were made at 24 hours and for groups from 7 to 12 were made at 6 months. At each instance, six groups were evaluated.

Composition of materials used in the study (Table 1 ).

All samples were etched for 15 seconds with 35\% phosphoric acid, washed and blot dried.

Groups 1 and 7: Samples were treated with adper single bond.

Groups 2 and 8: Samples were treated with prime and bond NT.

Groups 3 and 9: Samples were treated with adper single bond, after receiving $5 \% \mathrm{NaOCl}$ for 60 seconds.

Groups 4 and 10: Samples were treated with adper single bond, after receiving $5 \% \mathrm{NaOCl}$ for 120 seconds.

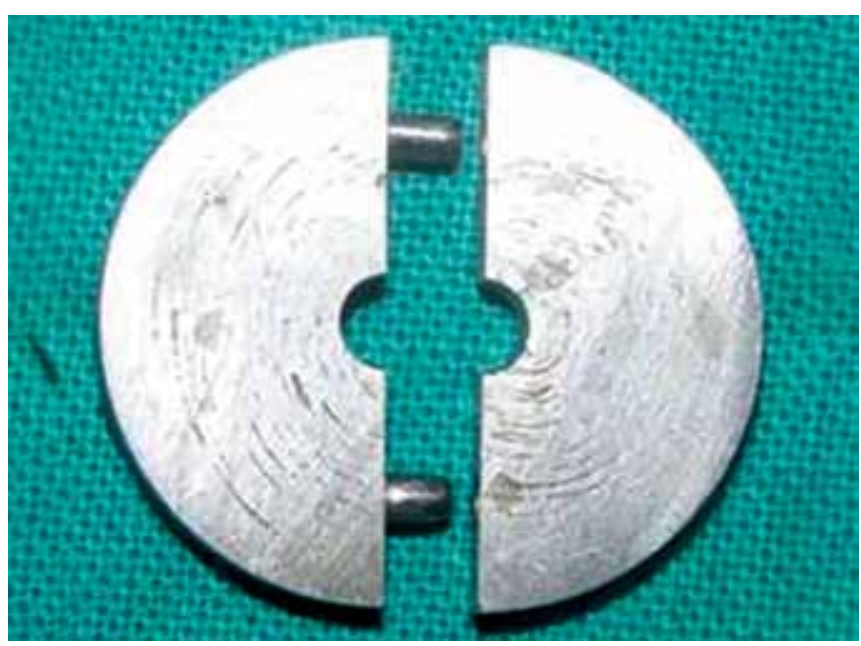

Fig. 2: Split mould 


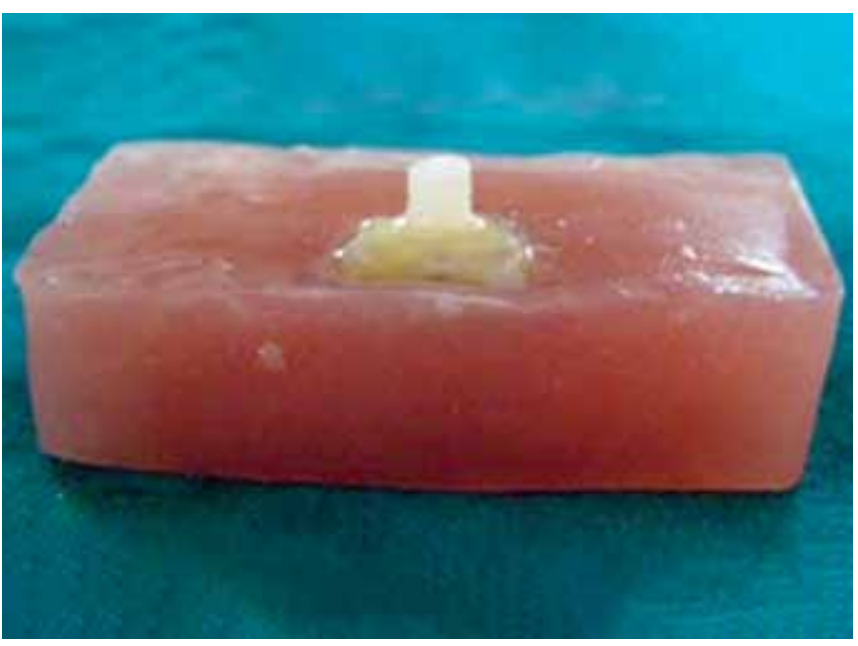

Fig. 3: Composite resin polymerized over the sample

Groups 5 and 11: Samples were treated with prime and Bond NT, after receiving $5 \% \mathrm{NaOCl}$ for 60 seconds.

Groups 6 and 12: Samples were treated with prime and bond $\mathrm{NT}$, after receiving $5 \% \mathrm{NaOCl}$ for 120 seconds.

The adhesive procedures were performed in accordance with the manufacturers' specifications.

To standardize the resin composite area and volume, a prefabricated metal device (split mould) as described by ISO was used. The split mould has an orifice $[3 \mathrm{~mm}$ in diameter and $3 \mathrm{~mm}$ height $(3 \times 3 \mathrm{~mm})]$ (Fig. 2). It was kept over the dentin surface that received the adhesive treatment, while preventing displacement when the resin composite (Z-100, 3M ESPE) was inserted and polymerized (Fig. 3). The specimens were submitted to a SBS test using a universal testing machine with a $50 \mathrm{~kg}$ load call at a speed of $1 \mathrm{~mm} /$ minute, in accordance with the standards described in ISO TR 11405. The force on fracture was recorded. When the specimens fractured, they were submitted to optic microscopy analysis and classified into four types, according to the plane of section for the fracture:

- Type 1: Cohesive fracture in resin composite,

- Type 2: Cohesive fracture in dentin,

- Type 3: Fracture in adhesive at the dentin/adhesive or adhesive/resin interface, and

- Type 4: A combination of cohesive and adhesive fractures

The data were submitted to ANOVA, Tukey's and paired t-test.

\section{RESULTS}

From the statistical data obtained, it was found out that deproteinization increased the SBS of prime and bond NT but reduced the bond strength of adper single bond (Table 2).

Using $5 \% \mathrm{NaOCl}$ for 60 seconds did not have any effect on the bond strength of both the adhesives used,
Table 2: Shear bond strength (MPa) to etched and deproteinized dentin obtained after 24 hours and 6 months period of water storage. Mean values

\begin{tabular}{|c|c|c|c|c|}
\hline Groups & $\begin{array}{l}\text { Storage } \\
\text { period }\end{array}$ & Type of dentin & $\begin{array}{l}\text { Mean } \\
\text { SBS }\end{array}$ & $\begin{array}{l}\text { Standard } \\
\text { deviation }\end{array}$ \\
\hline 1 & 24 hours & Etched dentin & $10.92^{\mathrm{ab}}$ & 1.65 \\
\hline 2 & 24 hours & Etched dentin & $12.48^{b d}$ & 1.25 \\
\hline 3 & 24 hours & $\begin{array}{l}\text { Deproteinized dentin } \\
\text { (60 seconds) }\end{array}$ & $10.96^{a b}$ & 2.45 \\
\hline 4 & 24 hours & $\begin{array}{l}\text { Deproteinized dentin } \\
\text { (120 seconds) }\end{array}$ & $7.57^{\mathrm{c}}$ & 1.45 \\
\hline 5 & 24 hours & $\begin{array}{l}\text { Deproteinized dentin } \\
\text { ( } 60 \text { seconds) }\end{array}$ & $13.01^{\text {bd }}$ & 1.00 \\
\hline 6 & 24 hours & $\begin{array}{l}\text { Deproteinized dentin } \\
\text { (120 seconds) }\end{array}$ & $17.79^{\mathrm{e}}$ & 4.26 \\
\hline 7 & 6 months & Etched dentin & $7.74^{c}$ & 1.41 \\
\hline 8 & 6 months & Etched dentin & $7.74^{\mathrm{c}}$ & 6.96 \\
\hline 9 & 6 months & $\begin{array}{l}\text { Deproteinized dentin } \\
\text { ( } 60 \text { seconds) }\end{array}$ & $6.89^{c}$ & 1.75 \\
\hline 10 & 6 months & $\begin{array}{l}\text { Deproteinized dentin } \\
\text { (120 seconds) }\end{array}$ & $8.91^{\mathrm{ac}}$ & 1.49 \\
\hline 11 & 6 months & $\begin{array}{l}\text { Deproteinized dentin } \\
\text { ( } 60 \text { seconds) }\end{array}$ & $11.74^{\mathrm{ab}}$ & 0.87 \\
\hline 12 & 6 months & $\begin{array}{l}\text { Deproteinized dentin } \\
\text { (120 seconds) }\end{array}$ & $14.85^{\mathrm{de}}$ & 2.52 \\
\hline
\end{tabular}

For each adhesive, values with the same letter are not different at $p=0.05$

Table 3: Types of fracture occurred in the various groups

\begin{tabular}{llllll}
\hline & & \multicolumn{4}{c}{ Type of fracture } \\
\cline { 3 - 6 } Sample no. & Storage time & Type 1 & Type 2 & Type 3 & Type 4 \\
\hline Group 1 & 24 hours & 0 & 0 & 7 & 3 \\
Group 2 & 24 hours & 0 & 0 & 8 & 2 \\
Group 3 & 24 hours & 0 & 0 & 6 & 4 \\
Group 4 & 24 hours & 0 & 0 & 7 & 3 \\
Group 5 & 24 hours & 0 & 0 & 7 & 3 \\
Group 6 & 24 hours & 0 & 0 & 9 & 1 \\
Group 7 & 6 months & 0 & 0 & 6 & 4 \\
Group 8 & 6 month & 0 & 0 & 5 & 5 \\
Group 9 & 6 months & 0 & 0 & 8 & 2 \\
Group 10 & 6 months & 0 & 0 & 7 & 3 \\
Group 11 & 6 months & 0 & 0 & 6 & 4 \\
Group 12 & 6 months & 0 & 0 & 5 & 5 \\
\hline
\end{tabular}

but when it was used for 120 seconds it changed the bond strength significantly.

The bond strength after 24 hours was significantly higher than the bond strength measured after 6 months (Table 2).

The majority of fractures that occurred were either adhesive or mixed. No cohesive fracture occurred in either resin or in dentin (Table 3).

\section{DISCUSSION}

Sodium hypochlorite is a deproteinizing agent that can be used to remove collagen from demineralized dentin and provide adhesion. ${ }^{8-10}$ This step opens the dentinal 
tubules to facilitate the access pathways for resinous monomer and favors the formation of extremely porous mineral surfaces, whose characteristics are similar to those of enamel. ${ }^{7,11,12}$

The speed of diffusion is another important factor in resin monomer permeation. The adhesive systems that contain bisphenol a glycidyl methacrylate (Bis-GMA) and triethylene glycol dimethacrylate (TEGDMA) have a slow diffusion speed, as these monomers are highly hydrophobic. By contrast, adhesives containing hydroxyethyl methacrylate (HEMA), which is hydrophilic and has low molecular weight, offer easy and fast diffusion. Diffusion can be affected by the substance, i.e. used to dilute the resinous monomer, e.g. water, alcohol or acetone. ${ }^{13}$

Various studies have reported that the removal of collagen increases dentin bonding, depending on the

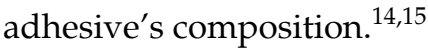

In the present study, when groups were evaluated after 24 hours, adper single bond showed significant decrease in SBS after deproteinization for 120 seconds, whereas prime and bond NT showed significant increase in SBS after deproteinization for 120 seconds.

Findings of this study, agrees with those of Barbosa D Souza F and Santos et al. ${ }^{16,17}$ Perdigao et al showed that the increase in the $\mathrm{NaOCl}$ application time resulted in a progressive decrease in SBSs for adper single bond, the application of $\mathrm{NaOCl}$ for 60 seconds resulted in a reduction of bond strengths to $38 \%$ of that obtained for the control. ${ }^{18}$

Reason behind the decrease bond strength of adper single bond after deproteinization was might be due to water/ethanol in its content, which has low ability to diffuse into dentin. ${ }^{7}$ Because of this, there is not probably enough time to completely fill the nanometric pores created by $\mathrm{NaOCl}$ in the intertubular dentin with monomers before polymerization. ${ }^{19}$ Author has found out that large molecule, such as polyalquenoic acid in Scotchbond MP and adper single bond which would make penetration of these adhesives into mineralized surface difficult. Furthermore, these adhesives are not very acidic $(\mathrm{pH}$ 3.5-4.2), this does not promote the second etch to dentin surface. ${ }^{20}$ Another phenomenon behind the decreased value of adper single bond was oxidizing effect of $\mathrm{NaOCl}$, which can be reversed by application of antioxidants. Lai et al have used sodium ascorbate to compensate with the deleterious effect of $\mathrm{NaOCl}$, which reversed the tensile bond strength to normal. ${ }^{21}$

Silva GO has showed increase in SBS of prime and bond NT after application of $\mathrm{NaOCl} .^{5}$ A similar type of study was done by using prime and bond 2.1 with and without using $\mathrm{NaOCl}$ by Saboia et al, concluded that collagen removal improves the bond strength for acetone based adhesive. ${ }^{19}$
Hydrolysis can occur at the adhesive interface over time. So long-term evaluation of SBS was done in the present study to see whether deproteinization can be applied to increase the service life of restorations and minimize the need for periodic replacement.

When analysis was made after 6 months, adper single bond revealed no significant difference to its deproteinized groups. Whereas prime and bond NT revealed significant increase of SBS in deproteinized groups.

Deproteinization using $\mathrm{NaOCl}$ was done at concentration of $5 \%$ for 60 and 120 seconds. For adper single bond (groups 3 and 4) showed statistical significant decrease after 120 seconds of deproteinization, i.e. group 4 . Values for group 3 was might be due to incomplete collagen removal as the concentration or the time of application was less.

For prime and bond NT (group 5 and 6) showed statistical significant increase after 120 seconds of deproteinization, i.e. group 6. This result echoes a 2005 study by Correr et al found that the concentration and application time of $\mathrm{NaOCl}$ interfered in the complete removal of dentin collagen. ${ }^{22}$

After storage time of 6 months groups 9 to 10 and groups 11 to 12 showed significant increase in bond strength values. When storage time alone was evaluated, groups evaluated after 6 months demonstrated significantly lower means than the groups evaluated at 24 hours. Furthermore, it was verified that the adper single bond obtained significantly lower mean bond strength at 6 months than prime and bond NT, regardless of whether $5 \% \mathrm{NaOCl}$ was used. The samples in groups 6 and 12 demonstrated statistically higher means than the other groups, in keeping with previous studies. ${ }^{16,18}$

In terms of the type of fracture that occurred, the majority of fractures were classified as type 3 (adhesive) and rest were type 4 (mixed). No cohesive fractures occurred in either resin or dentin.

It is possible for the correlation between adhesion and surface without collagen to present a higher relation with the type of adhesive agent employed due to the composition or possibility of interaction with residual hypochlorite. In accordance with Souza and others the chemical characteristics of the bonding agent $(\mathrm{pH}$, type and amount of solvent, monomer, presence of inorganic particles) may exercise decisive influence over adhesion to deproteinized surface. ${ }^{16}$ According to Pioch et al and Inai et al agents that contain acetone in their composition show better behavior in dentin deproteinization surfaces. ${ }^{12,23}$

Hence, there was better monomer interaction with the intertubular dentin structure exposed through $\mathrm{NaOCl}$ treatment, enabling penetration of the monomer into the substratum porosities. Another consequence of the 
higher acetone level in prime and bond NT would be affecting the solvents ability to promote the volatilization of free radicals of oxygen released by $\mathrm{NaOCl}$, which could interfere with the bonding agent polymerization process. Moreover, the acidic resin monomer of prime and bond NT ( $\mathrm{pH}=2.3$ ) would be able to re-etch the mineral phase of the dentin surface, further reducing the amount of collagen with a depth no greater than 0.3 to $0.5 \mathrm{~nm}$, thus producing nanohybrid layer large enough to ensure an optimized adhesion. In addition, the presence of phosphate terminals from phosphoric acid ester (PENTA) in the composition of prime and bond NT was verified. Phosphate terminals may establish some kind of interaction with calcium ions left over after collagen removal of the dentin surface. ${ }^{23}$

Based on the literature concerning increased bond strength, the deproteinization technique appears very promising only for acetone based adhesives. This method increases a step but also increases the service life of restorations and minimizes the need for periodic replacement. However, because degradation occurs over time due to the presence of dentin collagen at the bond interface, clinical independent longitudinal studies are still required to confirm the efficacy of $\mathrm{NaOCl}$ use, so that a technique that favors a stable bond to dentin may be developed.

\section{CONCLUSION}

Dentin deproteinization with $5 \% \mathrm{NaOCl}$ for 120 seconds may improve the bond strength of certain adhesives but depends upon the composition of bonding agent. Also the bond strength after 24 hours was significantly higher than the bond strength measured after 6 months.

\section{REFERENCES}

1. Buonocore MG. A simple method of increasing the adhesion of acrylic filling materials to enamel surfaces. J Dent Res 1955; 34(6):849-853.

2. Fusayama T, Nakamura M, Kurosaki N, Iwaku M. Nonpressure adhesion of a new adhesive restorative resin. J Dent Res 1979;58(4):1364-1370.

3. MeerbeekV,Dhem A, Goret-Nicaise M, Braem M, Lambrechts P, Vanherle G. Comparative SEM and TEM examination of the ultrastructure of the resin-dentin interdiffusion zone. J Dent Res 1993;72(2):495.

4. Sano H, Shono T, Takatsu T, Hosoda H. Microporous dentin zone beneath resin-impregnated layer. Oper Dent 1994;19(2): 59-64.

5. Silva GO, Barcellos DC, Pucci CR, Borges AB, Torres CRG. Longitudinal bond strength evaluation using the deproteinized dentin technique. General Dentistry 2009;57(2):328-333.
6. Wakabayshi, Kondou Y, Suzuki K, Yatani H, Ynmasbita A. Effect of dissolution of collagen on adhesion to dentin. Int J Prosthodont 1994;7(4):302-308.

7. Vargas MA, Cobb DS, Armstrong SR. Resin-dentin shear bond strength and interfacial ultrastructure with and without Hybrid layer. Oper Dent 1997;22(4):159-166.

8. Uno S, Finger WJ. Function of the hybrid zone as a stressabsorbing layer in resin-dentin bonding. Quintessence Int 1995;26(10):733-738.

9. Kanka J III. Resin bonding to wet substrate. I. Bonding to dentin. Quint Int 1992;23(1):39-41.

10. Van Meerbeek B, Inokoshi S, Braem M. Morphological aspects of the resin-dentin diffusion zone with different dentin adhesive systems. J Dent Res 1992;71(8):1530-1540.

11. Perdigoa J, Swift EJ. Analysis of dental adhesive systems using scanning electron microscopy. Int Dent J 1994;44(4):349-359.

12. Pioch T, Kobaslija S, Huseinbegovic A, Muller K, Dorfer CE. The effect of $\mathrm{NaOCl}$ dentin treatment on nanoleakage formation. J Biomed Mater Rest 2001;56(4):578-583.

13. Watanabe I, Nakabavashi N. Bonding durability of photocured phenyl-P in TEGDMA to smear layer-retained bovine dentin. Quintessence Int 1993;24(5):335-342.

14. Abo T, Asmussen E, Uno S, Tagami J. Short- and long-term in vitro study of the bonding of eight commercial adhesives to normal and deproteinized dentin. Acta Odontologica 2006; 64(4):237-243.

15. De Castro AK, Hara AT, Pimenta LA. Influence of collagen removal on shear bond strength of one-bottle adhesive systems in dentin. J Adhes Dent 2000;2(4):271-277.

16. de Souza BF, Silva CH, Dibb GPR, Delfino SC, de Souza CBL. Bonding performance of different adhesive systems to deproteinized dentin: microtensile bond strength and scanning electron microscopy. J Biomed Mater Res B Appl Biomater 2005;75(1):158-167.

17. Santos DPH, Sinhorita MOC, Consani S, Sabrinho LC, Abado GL. Effect of cyclic compressive loading on the bond strength of adhesive system to dentin after collagen removal. J Adhes Dent 2005;7(2):127-131.

18. Jorge P, Jefrey T. An ultramorphological characterization of collagen-depleted etched dentin. Am J Dent 1999;12(5): 251-255.

19. VdePA Saboia, Rodrigues AL, Pimenta LAF. Effect of collagen removal on shear bond strength of two single-bottle adhesive systems. Oper Dent 2000;25(5):395-400.

20. Prati C, Chersoni S. Effect of removal of surface collagen fibrils on resin dentin-bonding. Dent Mater 1999;15(15):323-331.

21. Lai SCN, Mak YF, Cheung GSP, Osorio R, Toledano M, Carvalho RM, Tay FR, Pashley DH. Reversal of compromised bonding to oxidized etched dentin. J Dent Res 2001;80(10): 1919-1924.

22. Correr GM, Alonso RC, Grando MF, Borges AF, PuppinRontani RM. Effect of sodium hypoclorite on primary dentin: a scanning electron microscopy (SEM) evaluation. J Dent 2005; 34(7):454-459.

23. Inai N, Kanemura N, Tagami J, Watanabe L, Marshall SJ, Marshall JW. Adhesion between collagen depleted dentin and dentin adhesive. Am J Dent 1998;11(3):123-127. 